Article

\title{
Global Challenges as Opportunity to Transform Business for Good
}

\author{
Chris Laszlo * (D), David Cooperrider and Ron Fry \\ Department of Organizational Behavior, Weatherhead School of Management, Case Western Reserve University, \\ Cleveland, OH 44106, USA; David.cooperrider@case.edu (D.C.); Ron.fry@case.edu (R.F.) \\ * Correspondence: Chris.laszlo@case.edu
}

Received: 27 August 2020; Accepted: 25 September 2020; Published: 29 September 2020

\begin{abstract}
Using insights from Peter Drucker's Theory of the Business framework, the authors show that global challenges such as pandemics and climate change are contributing to a critical misalignment between businesses and their increasingly complex external environments, leading to a growing malaise in many organizations. Central to this misalignment are seven legacy assumptions which no longer serve businesses effectively. Seven new assumptions better reflect today's external environment and point to how businesses can thrive ("Do Well") by making a positive difference in society ("Do Good.") The authors propose a set of change management methods and tools along with specific steps that leaders and organizations can take to transform their businesses into what they define as Positive Institutions.
\end{abstract}

Keywords: organizational functioning; leadership; transformation; purpose; positive institutions; appreciative inquiry; sustainable value

\section{Introduction}

Pandemics, climate change, and many other social and global challenges present an unusual opportunity to transform the role of business in society. It begins by replacing shareholder primacy with greater purpose as the North Star for a company's direction of travel. With such a transformation, businesses exist not to make a profit but to make a positive impact on communities and the natural world. Many companies are discovering that leadership for good is becoming a key differentiator. "The coronavirus pandemic will put more companies under scrutiny for decisions that impact employees, customers and society," notes Morgan Stanley [1].

Amidst the current pandemic, some industry leaders were furloughing employees while simultaneously paying out quarterly dividends and seeking raises for their CEOs [2]. Others such as Apple, Unilever, and PepsiCo were compensating their employees, including contractors, and extending their health benefits. Google created a COVID-19 fund for temporary staff and vendors to benefit from paid sick leave if they had potential symptoms of the disease or could not come into work because they were quarantined. Starbucks extended its mental health benefits. Comcast, Charter, Verizon, Google, T-Mobile and Sprint pledged to keep Americans internet-connected for two months during the height of the pandemic even for those who could not afford to pay [3]. Beyond these time-bound examples, more than 3000 stories of profitable business innovations that make a positive impact on society can be found on the AIM2Flourish platform [4]. These innovation stories provide compelling evidence that enterprise success can result from doing good for society and the environment.

Greater purpose and leadership for good are not new concepts. The 20th century's most revered management thinker, Peter Drucker, believed that a functioning society is created and sustained by organizations whose purpose is to serve the common good. Drucker believed businesses exist to serve society. His Five Most Important Questions, shown in Figure 1, began with "What is Our 
Purpose?" This was later changed to "What is Our Mission?" but Drucker on several occasions observed that purpose was antecedent to, and more fundamental than, vision and mission [5].

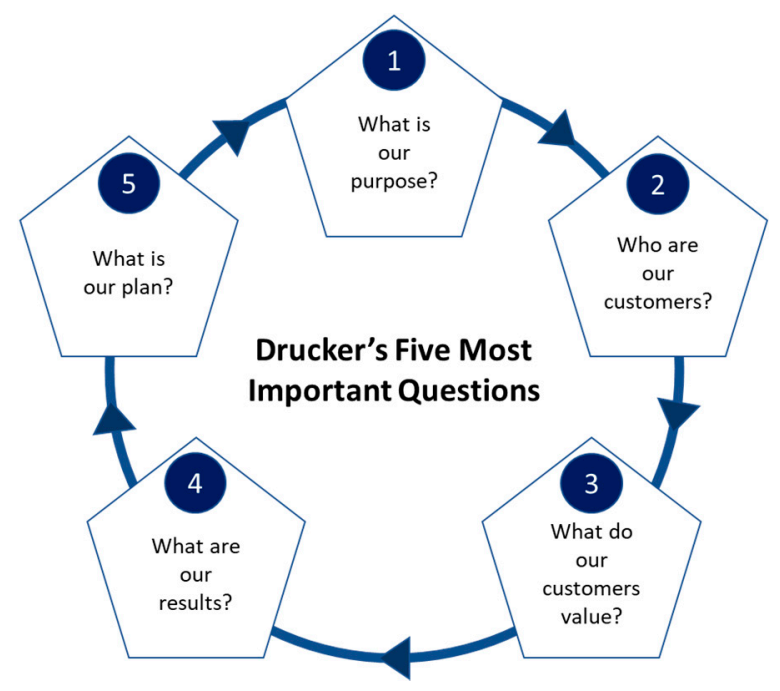

Figure 1. Drucker's Five Most Important Questions [5].

In his 1994 Harvard Business Review article, The Theory of the Business [6], Drucker observed that "what underlies the malaise of so many large and successful organizations worldwide is that their theory of the business no longer works" [6] (p. 96). Put another way, he said, "reality has changed, but the theory of the business has not changed with it" [6] (p. 98). This statement is profoundly relevant to understanding the malaise that organizations are experiencing today [7]. Drucker wrote, "The assumptions about environment define what an organization is paid for. The assumptions about mission define what an organization considers to be meaningful results; in other words, they point to how it envisions itself making a difference in the economy and in the society at large" [6] (p. 100).

Drucker's theory of the business can help us reevaluate deeply held beliefs that shape an organization's functioning including its assumptions about market expectations and the values held by its customers or communities; about technology and its dynamics; about the theory of value; and about the purpose of business in society. All of these elements are being disrupted today by challenges such as pandemics and climate change.

We propose that businesses will benefit immediately from exploring Drucker's insights by asking the following questions.

- What legacy assumptions about the business environment no longer serve us well?

- What new assumptions better reflect the emerging environment that we operate within?

- How might these new assumptions help our organization thrive? This involves re-thinking how we make a positive difference in the economy and society.

- What management methods and tools are newly relevant for environments hallmarked by disruptive global challenges?

\section{Theoretical Framework}

Throughout the paper, we draw on a modified form of the widely-cited Burke-Litwin model of organizational behavior [8]. According to the model, organizational performance and change are best explained by four transformational factors, seven transactional ones, and their interrelationships. We focus at the transformational level-which includes the firm's external environment, mission and strategy, leadership, and culture-where the need for realignment has become vital and urgent. As Burke and Litwin observed nearly 30 years ago, "Organizational effectiveness is contingent, in part, on the degree of match between the organization's external environment (whether static or dynamic) 
and the organization's internal structure (either mechanistic or organic)" [8]. (p. 525). Our proposed modification is to develop the dynamic and organic aspects mentioned in the previous sentence to reflect the higher degree of emergence, non-linear causality, and complexity than what may have been apparent to Burke and Litwin at the time of their research. This modified Burke-Litwin model recognizes explicitly the need for a dynamic fit between the firm and its complex emergent environment. The notion of dynamic fit borrows from Ilya Prigogine's dissipative structures theory of thermodynamic systems for which he won the Nobel Prize [9]. The idea of "fit" thus reflects emergence rather than a static outcome. We view the relationship between an organization and its environment as a dynamic equilibrium in the sense of it being emergent, non-linear, and complex yet exhibiting underlying order. Such "order" is better understood as ordering, where rapidly emerging patterns necessitate discontinuous innovation and adaptation.

We contend that the degree of mismatch between the firm and its complex external environment is worse now than at any point since the Mont Pelerin Society's founding in 1947 when free-market capitalism was relaunched by a small group of conservative economists and industrialists to counter the perceived threat of Marxism and fascism spreading throughout Europe [10].

We examine the benefits of realigning a company's leadership and culture as a function of this emerging external environment which, in the Burke-Litwin model, is the "input" that drives the business system's "output" of individual and organizational performance. We do so through the lens of Sustainable Value, which we define as a dynamic state that occurs when a company creates ongoing value for its shareholders and stakeholders [11]. Next, we offer a set of change management methods and tools effective in complex and turbulent environments. The last section proposes specific steps that companies can take to improve their organizational functioning and change management.

\section{Materials and Methods: A Critical Assessment of Assumptions about the Business Environment}

COVID-19 and climate change reflect a trend of social and global challenges that are continuing to grow in frequency and amplitude. They highlight the complexity, interdependence, and non-linear nature of our world. The majority of such challenges do not respect borders and can threaten to engulf all people irrespective of geography or personal circumstance. The list of such challenges includes rising social inequality, systemic racism, growing refugee crises, chronic food insecurity, mass shootings, opioid abuse, and a catastrophic loss in biodiversity.

Each of these challenges is in some measure causally dependent on all the others, as reflected in the following plea by a climate scientist.

"I need you to become actively anti-racist. I need you to understand that our racial inequality crisis is intertwined with our climate crisis. If we don't work on both, we will succeed at neither." Marine biologist Dr. Ayana Elizabeth Johnson [12]

At the root of businesses' inability to respond to such challenges are assumptions that are now outdated, and even dangerous, vestiges of a 20th century neoliberal ideology. Systems scientist Donella Meadows referred to them as "the shared idea in the minds of society, the great big unstated assumptions-unstated because unnecessary to state; everyone already knows them-[that] constitute that society's paradigm, or deepest set of beliefs about how the world works" [13]. Here we examine seven such legacy assumptions which businesses in every sector must question-and in many cases shed-to survive and thrive in the years ahead.

\subsection{Seven Legacy Assumptions}

\subsubsection{The More We Grow, the Better off We Are}

The first such legacy assumption is that economic growth is an end in itself. A growing number of economists from Oxford University's Kate Raworth (Doughnut Economics) to Harvard's Rebecca 
Henderson (Reimagining Capitalism in a World on Fire) are sounding the clarion call questioning the myth of infinite growth on a finite planet. Teenage activist Greta Thunberg gave further visibility to the issue when she berated world leaders at a United Nations Climate Action Summit with the words, "We are at the beginning of mass extinction, and all you can talk about is money and fairy tales of eternal economic growth."

During the current pandemic, the assumption that economic growth can cure all ills was reflected in U.S. policies of keeping the country "Open for Business". Early in the pandemic, this gospel of growth was characterized as "the notion that Americans cannot afford to save tens of thousands, even hundreds of thousands, of lives, if it means sacrificing a quarter or two of gross domestic product" [14]. For those living paycheck-to-paycheck, the choice between going back to work and observing public health guidelines was stark. Whichever perspective you held, the debate over jobs versus lives was likely to shake your unqualified belief in economic growth as a universal panacea.

\subsubsection{The More We Shop, the Happier We Are}

A related assumption is that people are primarily interested in higher paying jobs and, with the additional income, pursue unbounded material consumption. Clinical research in the last few decades shows that people who experience wellbeing-who flourish in the sense of living life to its fullest-depend on emotional and relational factors to achieve a life of happiness and fulfillment [15]. Rather than focusing only on maximizing financial success and material consumption, studies repeatedly demonstrate the importance of feeling deeply connected to self, others, nature, and the transcendent as the key to personal flourishing [16]. For many, and especially Millennials, the switch from materialism to a more austere way of life may not even be a matter of choice: the damage done by the Great Recession of 2008-09 and COVID-19 only a decade later will mean that the large houses, cars, and retirement savings of their parent's generation may be unattainable in their lifetimes.

Our fascination with economic growth and material consumption will no doubt return in some form after COVID-19 has run its course. Yet its scope and severity will leave behind an enduring sense that we cannot take for granted our health and wellbeing. We are learning the hard way that buying "stuff" in a world obsessed with economic growth-and its benchmark the Gross Domestic Product (GDP)—is not the pathway to happiness [17].

\subsubsection{We Progress Fastest by Focusing on What's Wrong}

A third legacy assumption is that studying problems ("what happens when things go wrong") can make us an expert in delivering solutions ("how to make things go right"). What is sometimes called deficit-based management ruled business for much of the 20th century with its decision-making processes of problem identification, root cause analysis, and piecemeal action plans. Executive teams of 7-9 members brainstormed reductionist solutions that had little ownership inside or outside the business.

Psychologists studied the pathologies of the mind and medical doctors studied the diseases of the body. In the field of management, scholars analyzed what happened when companies went out of business. Starting with the collapse of the Medici Bank in 1494, the popular imagination was captivated by spectacular corporate failures. Familiar cases of the last thirty years include Pan Am Airways, Commodore Computers, Enron, Lehmann Brothers, and more recently Blockbuster Video, Borders, Kodak, and Thomas Cook. Business scholars and practitioners hoped to learn what goes right from what went wrong. Yet evidence consistently suggests that only about 30 percent of change programs rooted in such traditional deficit-based approaches actually succeed in improving individual or organizational performance [18].

\subsubsection{The Rights of the Individual Trump any Responsibility to the Collective}

A long history of individualism in Western countries emphasizes autonomy, individual responsibility and achievement, and self-reliance. The right of the individual to freedom and 
self-realization permeates many Western cultures and values, but what happens when these countries are faced with social and global challenges such as pandemics and climate change that require collective action? The response to COVID-19 helps illustrate this quandary. In the U.S. at the height of the pandemic, the right to individual freedom was captured in the classic image of a quarter of a million motorcycle riders and enthusiasts descending on Sturgis, South Dakota, for the 80th Sturgis Motorcycle Rally, most of them without masks and ignoring social distancing at an event that was voted down by a majority of the city's residents [19]. Behaviors such as a refusal to wear masks or to observe social distancing in large crowds put more people at risk of the disease and, ultimately, increase economic cost.

The choice should not be between individualism and collectivism. Nor is it helpful to frame the issue as capitalism versus socialism, freedom versus fascism. Rather we need a new path that marries free-market democracy with civil responsibility for the collective. The right of each individual to their own life and happiness must not come at the expense of the community, now or for future generations.

\subsubsection{Government Regulation Is Contrary to Freedom, Equality, and Justice}

Many pundits in the West believe that government in all its forms should be limited as much as possible and that free markets should be unfettered by regulators. At his presidential inauguration, Ronald Reagan proclaimed that "in this present crisis government is not the solution; government is the problem" [20]. U.K. Prime Minister Margaret Thatcher echoed a similar view across the Atlantic. According to these political leaders, big public corporations as well as entrepreneurs and family-owned businesses are best left alone to compete in a free enterprise system unencumbered by government agency.

Harvard business school professor Rebecca Henderson cites evidence from 2019 that trust in government is at an all-time low [21]. She points to a concerted effort by a network of conservative economists and wealthy business leaders, such as the Koch brothers, to discredit government intervention in the American economy. Between 2016 and 2020, the Trump administration actively reduced government regulations in areas ranging from labor, finance, and transportation to health, the environment, and human rights. The consequences have been weaker property rights, cronyism, rising income inequality, anticompetitive monopolies, increased damage to the social safety net, and the decline of American power abroad [22].

\subsubsection{Nature Is a Resource for Consumption}

A sixth assumption is that humanity is somehow separate from, and above, other forms of life. Nature is viewed as an economic resource. At best we have seen ourselves as stewards and at our worst as consumers of the oceans, grasslands, tundra, forests, and the varied forms of life they support. Because of human activity, the earth is reaching critical thresholds beyond which its ability to support life as we know it is at risk. By June 2020, the Keeling curve, which shows the accumulation of carbon dioxide $\left(\mathrm{CO}_{2}\right)$ in the earth's atmosphere, had reached 415 parts per million (ppm). For reference, atmospheric $\mathrm{CO}_{2}$ had remained under $300 \mathrm{ppm}$ for all of the last 3 million years of recorded history [23]. Scientists have now established with a high degree of certainty that a direct linear relationship exists between human-induced $\mathrm{CO}_{2}$ accumulation and global warming [24].

Besides climate change, three other planetary boundaries have been exceeded as a result of human activity. These include the loss of biosphere integrity due to ecosystem damage and species extinctions, land-system change due to cropland conversion, and altered biogeochemical cycles (primarily phosphorus and nitrogen) [25]. Crossing these boundaries is increasing the risk of large-scale disruption of the complex natural balances that allow for life as we know it.

The direst outcomes in terms of the health and wellbeing of future generations will only be avoided if the negative impacts of businesses are slowed and ultimately reversed. The impact horizon continues to shorten so that what used to be consequences far into the future are affecting many people 
and other forms of life today. For example, coastal communities are being affected now by rising sea levels and many eco-systems are threatened by both climate change and crop land conversion.

\subsubsection{Science Must Be Viewed with Skepticism}

The seventh assumption prevalent in business and society is that science is overrated and that ideological beliefs can carry us through if stated with enough conviction [26]. Look what that got us in the early phases of COVID-19. A lasting trace of the pandemic combined with growing climate change disasters will eventually force a return to more evidence-based policies from experts who rely on grounded research to make their recommendations. While aspirational conviction can be a powerful force for good, in our view it must be balanced by a measure of trust in scientists who act in the public interest. At the same time, we are also finding out the hard way that evidence-based learning can be too slow to make effective decisions and choices in situations of unprecedented complexity. In order to flourish, emergent complex systems require science-based decision-making combined with real-time whole system approaches such as those used in the Appreciative Inquiry Summit methodology discussed later in this article [27].

New assumptions are needed to better reflect local and global realities. For example, climate change will only worsen in the years ahead, bringing with it new disease vectors, crop failures, respiratory diseases, biodiversity loss, and other system wide failures. Many complex challenges are embedded in the 17 Sustainable Development Goals (SDGs) [28], from quality education to reduced inequality and strong institutions capable of ensuring peace and justice. They call for businesses in every sector to provide solutions of public interest (a.k.a. a positive handprint) by creating disruptive innovations that are not only profitable but also benefit society and the environment.

\subsection{Seven New Assumptions That Better Reflect the Emerging Business Environment}

We propose seven new assumptions that can offer business scholars and practitioners the basis for a more relevant Theory of the Business, as Drucker conceived it. As was the case for the seven legacy assumptions, our list is not meant to be exhaustive. It is intended to generate further inquiry and exploration in the academic and business communities.

\subsubsection{Companies Do Well by Doing Good}

Business as an Agent of World Benefit (BAWB) can become the new purpose of economic activity. In this framing, revenue and profit derive in whole or in part from improving human wellbeing, solving social and global problems, and generating prosperity for all. Greystone Bakery's Open Hiring model aimed at improving social mobility and OAT Shoes' sneakers that biodegrade and bloom into flowers are colorful illustrations of such a greater purpose in business.

Patagonia's "We're in Business to Save the Planet," Unilever's "Sustainable Living Plan," IKEA's "People and Planet Positive Strategy," Tesla's "Accelerate the world's transition to sustainable energy," Ørsted's "A World that Runs Entirely on Green Energy," Warby Parker's "Buy a Pair Give a Pair," and Natura's "Well-Being and Being-Well" are only the tip of the iceberg. The previously cited AIM2Flourish platform showcases thousands of such profitable business innovations that restore, heal, or strengthen social and ecological systems [29]. Many such innovations involve a conversion from extensive growth models that depend on massive material resource use of land, fossil fuels, and other nonrenewable inputs to intensive growth models designed around providing a service rather than a product, asset sharing, renewable materials, and intangible value such as emotional and spiritual wellbeing. The switch from extensive to intensive growth is an essential component for businesses to succeed in the face of the rising negative consequences of unfettered economic growth.

\subsubsection{Positive Institutions Are Essential to a Flourishing World}

Positive Organizational Scholarship (POS) [30] is helping to usher in an era of Positive Institutions, defined here as "institutions that not only elevate our highest human strengths and combine those 
strengths within the enterprise, but organizations that then take, magnify and refract our highest human strengths outward toward building a world of full-spectrum flourishing" [31]. Institutions on this path can be found in every sector of the economy including for-profit businesses, nonprofit organizations, government, and civil society.

Research into human behavior offers compelling evidence that people are more willing to change - and that the change is more enduring - when it is built on strengths rather than weaknesses and on positive images of the future rather than on negative emotions such as fear [32]. Building on strengths and using positive images of the future are both hallmarks of positive institutions. Such institutions function at their best when they "pull" people toward perceived desirable outcomes, as is the case for greater purpose, instead of pushing them away from negative ones.

Positive institutions hold the key to a flourishing world. Such a world can only be achieved by combining the strengths of business with the power of government, nonprofits, and civil society. Only then can we ensure that freedom, equality, and justice will remain the bedrock of a healthy democratic system that benefits all its members. As former Secretary General of the United Nations Kofi Annan put it, "Let us choose to unite the strengths of markets with the power of universal ideals ... let us choose to reconcile the creative forces of private entrepreneurship with the needs of the disadvantaged and the requirements of future generations" [33].

\subsubsection{Flourishing Employees Are Essential for Positive Institutions}

Notwithstanding the cliché that "our employees are our most important asset," economic theory and management practice have tended to treat individuals as no more than efficient cogs in a machine (which coincidentally is how unhappy employees say they feel in their workplace) or as transactional inputs who seek only to maximize material rewards. Yet without flourishing individuals and the energy, commitment, ingenuity, citizenship, and creativity they bring, we cannot expect positive institutions to support flourishing at the scale of the whole. This is particularly relevant when we view our institutions not as mechanistic and predictable but as the consequence of complex responsive processes [34]. In this view, organizing occurs through a complex web of interactions embedded in conversations, each with infinite potential. The more that each participant in these conversations can bring their flourishing selves-healthy, talented, curious, energetic, aspirational, thoughtful, and creative- the more the organization can innovate and flex in turbulent environments.

Thus, businesses must learn to see employees as more than a productive resource or asset to be used as efficiently as possible. The task of management must include attending to the wellbeing of each employee as a whole person. To see someone as a whole person, we must assume that they have integrity of being, that their emotional and spiritual health is taken into account along with their material needs enabled by, for example, living wages. The people who are part of a positive institution become transformed, in everyone's thinking, from mere economic production functions to real, living individuals who are able to bring their full repertoires of passion, knowledge, and talents to work. Highly engaged employees evidence this whole person commitment to the workplace. Research over the past few decades is convincing in showing that high engagement is one of, if not the, best predictor of organization success [35]. Because our places of work play such an important role in all our lives, for the good of the firm and the good of the person, business organizations that serve the whole human being and not just the economic part of each person will outperform those that do not take such a view [36].

\subsubsection{Collaborative Partnership between For-Profits, Nonprofits, and Governments Benefit All Parties}

Cross-sector collaborations are now a requirement for solving complex social and global challenges. As early as 2013, a United Nations Global Compact (UNGC) and Accenture survey of over 1000 CEOs found that while they largely shared the view that sustainability was a key source of competitive advantage, they believed that it could only be achieved with the help of government and nonprofit partnerships [37]. 
SDG 17 is "Partnerships for the Goals." It is based on the idea that sustainable development can only be realized with strong global partnerships and cooperation that mirror the interconnected wholeness of the world in which business operates. It speaks to the need for cross-sector and cross-country collaboration. Because the 17 SDGs are interconnected and affect each other in multiple ways, SDG 17 can be considered to be the glue that holds together all the other goals.

Indeed, building a future-fit and future-forming theory and practice of business is a collective affair, where each adjacent innovation - whether in business models, products, or processes-adds to the number of achievable possible innovations. The task of leadership becomes designing configurations of the whole through system-wide collaboration and cooperation. As the economist Jeffery Sachs observed, the single most important factor affecting our fate is our capacity for human cooperation which, he writes, "is a fundamental point of blinding simplicity" [31].

\subsubsection{Stakeholder-Centric Forms of Incorporation Are Good for Shareholders}

Management scholars Donaldson and Walsh observed, "Society expects more from business these days than simply creating wealth ... Entirely new legal entities have recently emerged to serve this kind of ambition. The low-profit limited liability corporation and the benefit corporation, for example, are innovative attempts to create companies that pursue profit and social good simultaneously ... Change is in the air" [38].

Stakeholder-centric forms of incorporation such as the B Corp and L3C have emerged to protect managers from shareholder lawsuits aimed at eliminating initiatives that create value for society and the environment. Ironically, the success of these new legal forms is proving that creating value for business and society can create even more value for customers and shareholders [39]. In other cases, the founder's intent is social impact even if it means lower profits. Some forms of social entrepreneurship may calculatedly accept a lower return on invested capital (ROIC), as exemplified by Danone-Grameen, founded in partnership with Nobel Prize winner Muhammad Yunus in 2007 to produce fortified yogurt for malnourished children in Bangladesh.

3.2.6. Technologies Such as Artificial Intelligence and Big Data Are Gateways to Creating Positive Value for Business and Society

Harvard biologist E.O. Wilson proclaimed that "the real problem of humanity is the following: we have Paleolithic emotions; medieval institutions; and god-like technology" [21] (p. 7). The promise of cutting-edge technologies to drive profitable business innovations is exciting. The question is, business innovation for what purpose? Will technology be used without regard for socially-desirable consequences? Such an amoral stance was illustrated in the 2018 case of Cambridge Analytica, the big data firm that used data improperly obtained from Facebook to build voter profiles. Chief data scientist Alex Kogan claimed that he didn't know that his data collection app would be used for nefarious purposes. "I didn't really appreciate how business is done," he said at a later date [40].

Georg Kell, the chairman of global asset management firm Arabesque, emphasizes the ways in which hi-tech is helping businesses be more sustainable. "Technology has long been a key driver behind the sustainability movement by improving resource efficiency and facilitating the search for new business models," he notes. "For investors, technology—often based on machine learning and Artificial Intelligence-has become the bedrock of ESG [Environmental, Social, and Governance] investing, enabling greater transparency and the quantification of performance of non-traditional factors that have an impact on long-term financial performance" [41].

The business community's growing fascination with Artificial Intelligence and Big Data reflects both their profit potential and the opportunity they present to find solutions to many of the world's social and global challenges [42]. Only by integrating the two-profit and world benefit-will businesses realize the promise inherent in these technologies. 
3.2.7. The Highest Points of Leverage for Leadership Development Are Direct-Intuitive Practices That Transform a Person's Consciousness and Consequent Way of Being

Systems scientist Donella Meadows viewed mindset as the highest point of leverage for intervening in complex systems. The opportunity for business is to elevate a consciousness of connectedness through whole-person leadership development and change. Doing so requires leaders to change who they are being, not only what they are doing. They must go beyond rational-empirical analyses and beyond moral reasoning for doing good. It is only through experiencing wholeness and connectedness that leaders durably transform their awareness of how their actions impinge on others and nature. Such experiences have been shown to neuro-physiologically rewire a person at the deepest level of self-concept [43].

Consciousness research has rapidly entered the fields of neuroscience, the study of emotional intelligence, and mindfulness in management, as well as "leadership and the new science" with its worldview of fundamental interconnectedness. Such research is shedding new light on the capacity for direct-intuitive practices, including meditation, art, music, and exercise, to transform a leader's consciousness as the highest point of leverage for entrepreneurial creativity that embeds social purpose. Layered on top of such practices are insights from quantum science that offer a radically different view of organizational life [44]. Such insights help managers understand how the practices work to transform a person's way of being.

By giving people an experience of connectedness that increases their awareness of how their actions impact others and nature, and then reframing that experience through a lens of quantum science which describes reality in terms of wholeness and connectedness, leaders choose business as a force for good not only because of the analytic business case for it, which remains important, but because of how they see the world around them.

\section{Discussion}

The organizational implications of the Seven New Assumptions can be explored using a modified Burke-Litwin model. The discussion benefits from a focus on the model's transformational factors in a complex, dynamic, and emergent environment. The additional lens of Sustainable Value, as defined earlier, serves to highlight the value created for business and society.

The opportunity is to transform whole sectors of the economy during times of disruption. For example, the healthcare and the pharmaceutical industry could bifurcate toward putting patients first rather than increasing reliance on profit-centered models. High-tech could shift from offering product-centric tools to enabling complex business and society outcomes. Transportation and energy sector leaders such as Tesla and Ørsted are already disrupting existing industry models that are often capital-intensive, centralized, and dependent on fossil fuels, in favor of radically sustainable models that are based on distributed assets, circular value chains, and clean fuel technology. In every sector, companies adopting the new assumptions may be better positioned to hire and retain employees who are committed to business flourishing. Those that are stuck in legacy assumptions risk de-motivating employees who retreat into self-preservation and hanging on to their status or rights as a way to survive. The same opportunity for higher engagement is true for customers and investors who are actively seeking companies that do well by doing good.

Here we highlight two transformational factors (leadership and culture) from the Burke-Litwin model to emphasize their attributes in complex business environments.

\subsection{Transformational Factor: Leadership}

Previous research has highlighted the attributes of leadership in organizations that create sustainable value in ways reflecting the Seven New Assumptions about the business environment [45]. High-performing leaders in such organizations see the world in terms of wholeness and connectedness. They are driven by a sense of greater purpose, they tend to be highly relational, collaborative, and people-centric, and they are committed to cultivating the inner self. When the workforces 
in organizations believe in the purpose-driven sincerity of the leaders, they exhibit more creativity, higher engagement, and report more quality connections with their peers [46].

\subsection{Transformational Factor: Culture}

The same research highlighted the attributes of high-performing cultures in organizations that create Sustainable Value in complex and turbulent environments.

Such flourishing organizational cultures are people-centric and relational; creative and innovative; designed to promote well-being inside and outside the organization; and they operate from a strength-based perspective rather than a deficit-based one [45] (p. 132).

People-centric and relational cultures emphasize the interests and values of employees, clients, and other stakeholders of the organization [47]. Creative and innovative cultures are distinguished by design thinking in which abductive reasoning is as important as deductive or inductive logic. They are hallmarked by an appreciation for cultural diversity and local knowledge. Designed to promote well-being inside and outside the organization refers to cultures that enable an alignment of personal and organizational values. They allow employees to bring their whole selves to work and give priority to their work-life balance. Operating from a strength-based perspective rather than a deficit-based one refers to cultures that embed positive psychology and positive organizational development.

Our emphasis on the transformational aspects of leadership and culture are offered as an opening pivot in the journey toward positive institutions that do well by doing good. We leave it to the reader to build on these ideas in ways that further reflect organizational functioning and change management with a higher degree of dynamic fit between a firm and its external environment.

\section{Change Management Methods and Tools: Appreciative Inquiry and Sustainable Value}

Innovation is a precondition for building enterprises that authentically advance what we call "full spectrum flourishing," that is, a better future in which businesses prosper, people thrive, and nature flourishes. In this section, we propose a set of change management methods and tools aimed at such flourishing. The set is not intended to be exhaustive. It reflects our collective experience with best practices for developing positive institutions in complex and turbulent environments. We begin with what we consider to be the highest leverage pathway for launching a corporate-wide strategic pivot toward becoming an industry-leading star for advancing flourishing. We ask the questions: When is it that the best in human beings comes to the fore most easily, productively, and naturally? How do we engage others to go beyond isolated pockets of change to enterprise- and system-wide innovation?

Our answer from decades of field work interviewing hundreds of leaders who were going beyond the sustainable enterprise models of "less harm" to the journey and purpose of full spectrum flourishing, is unequivocal: "There is nothing that brings out the best in human enterprise faster, more consistently or more powerfully than calling the whole organization to design sustainability solutions to humanity's greatest challenges" [48]. The best in human systems comes to the fore when people collectively experience life-giving wholeness across multiple systems of key stakeholders, internal and external, embracing humanity and all forms of life. We are only partially beginning to understand its generative power in terms of quantum connectivity, concepts of super-coherence, collective consciousness, design thinking's positivity ratio, and the overview effect [49]. It is in this emerging context that one of the field's leading large-group approaches—the Appreciative Inquiry Summit method-has been singled out by a UN Global Compact report as "the best large group method in the world today" [50].

\subsection{Appreciative Inquiry Summit Method}

An Appreciative Inquiry Summit (AIS) is a research-based and game-changing large group meeting design that brings hundreds to several thousands of internal and external stakeholders into the room (or virtual space) to work on a task or sustainable design opportunity of strategic, and especially whole system, value creation. It is a powerful dialogic and active design-studio focused on a planning 
process over two and a half to three days, where everyone becomes engaged as co-designers to share the task of leadership and to take ownership for creating a future hallmarked by large and systemic opportunities for transformation. Each participant is invited in real-time to the centre of strategic thinking and implementation.

Imagine companies designing facilities that give back more abundantly renewable and clean energy to their communities than they use. Imagine companies bringing their local cities together-"strategic convening via the AIS" [51] - to design resilient economies that are carbon positive, regenerative, advance affordable and mixed income housing, turn waste to wealth, create better harmony with ecosystems, design institutions for racial justice, dignified work for all, and restore trust in democracy. Imagine companies inviting their Tier 1 suppliers to join them to collectively cut gigatons (one gigaton equals 1 billion metric tons) of greenhouse gas emissions across supply chains by 2030. Small to medium enterprises such as Vita-Mix and Clarke Industries as well as the largest enterprises in the world such as Apple, Walmart, Tata, and Novo Nordisk are embracing AIS approaches to think and act "beyond the possible."

While at first it may challenge our belief that groups of hundreds and sometimes thousands of people in the room can be effective in developing and implementing system-wide strategies, this is exactly what is happening in organizations that are taking the stakeholder theory of the firm to its logical and more value-creating next stage. Instead of seeing stakeholders as separate entities forcing companies to choose favorites or to become mired in trade-off analyses, the AIS method invites radical but exciting shifts:

1. It proposes that the idea of "external stakeholders" is a worldview mistake, and that an appreciative system approach specifically refutes the idea of organizations as autonomous, self-sufficient units as having an inside and an outside. It stresses the fact that all organizations are "wholes of wholes" that interpenetrate one another, thus constituting an intricate, functionally inseparable, network of vital relationships, interorganizational relatedness, stakeholder groupings and the ultimate envelope of enterprise, the biosphere.

2. The appreciative systems approach recognizes that the legacy conception of business-and its associated assumptions of "internal stakeholders" and "external stakeholders"—-seriously underestimates the synergy producing resources available to a business. It underutilizes assets and the vast and available "universe of strengths" in two ways. The first is that the so-called external stakeholders are rarely invited into the inner circle of strategy making-for example, how often do companies bring significant numbers of customers or community representatives to the table, with full voice, during the real-time planning of the future? The second is that it's even more rare to bring the whole system of stakeholder groups all together in real-time and into the inner circle of strategy for co-creating new designs, dreams, and strategic initiatives. In effect, legacy assumptions of business suppress what the literature calls network effects and "the concentration effect of chemistries of strengths".

3. It provides a third-form of leadership that is neither top down nor bottom up. The influential organizational behavior scholar and author Bob Quinn said in his book, Change the World: How Ordinary People Can Achieve Extraordinary Results, that "Appreciative Inquiry is revolutionizing the field of organization development and change" [52]. The AIS is a vital third form of management and it includes, but is not limited to, top down and bottom up approaches. It helps executives shift their eyes from the parts (a few stakeholders) to the whole (society and world) whereby entirely new options come into view. With the systems perspective, everyone experiences something of an overview effect-not unlike when astronauts zoom out and see the planet for the first time-and research shows that the experience of the whole brings out the best in human interaction and the capacity to see, appreciate, and leverage the underlying relationships that will allow everyone to better flourish [53]. 
As the CEO of Clarke Inc said of his first AIS to create the company's pivot to becoming a regenerative business:

"This whole system in the room process, with hundreds of stakeholders, was among the great high point moments in my leadership career. It generated an identity-shift for our entire business ... we call it Project Greater Purpose and our customers, the community leaders, supplier partners, and outside exemplar companies blew us away not only with their passion for our business but for the better product, production, and market-expanding prototypes we created, all focused on going beyond sustainability to regeneration. They contributed way beyond our wildest expectations and now I see it: it's that macro-magic moment when innovation happens, when strong multidisciplinary groups and stakeholder configurations come together, build a collaborative and appreciative interchange, and elevate upward and outward the intersection of their different points of strength" [54].

\subsection{Sustainable Value}

When you combine the AIS method with a focus on Sustainable Value, it unleashes generative connections and innovative thinking that, in many systems, would have previously been deemed impossible. By "doing good" for society and the environment, companies do even better for their customers and shareholders than they otherwise would. In its original form [55], the Sustainable Value construct highlighted value creation for a company's shareholders along one dimension and value creation for its stakeholders along another dimension. It compared the case of mutual value creation (when value is positive along both dimensions) with value transfer when shareholder value is created at the expense of stakeholders (or vice versa). A more dynamic construct shows business models, products, processes, and technologies shifting their ability to create value over time as stakeholder expectations and shareholder preferences change. For example, single-use polyvinyl chloride (PVC) consumer products, such as children's toys distributed in retail food chains, were once seen as creating value for both business and society. The same is true for cigarettes, coal, flame-retardants, red meat, palm oil, paper coffee cups, and disposable grocery bags. These products were once seen as value creating for both shareholders and stakeholders. Today such products are seen as destroying value for communities everywhere that are dealing with public health crises, accompanied by higher incidents of disease affecting the poor, as well as massive amounts of material waste and climate change.

A dynamic approach to Sustainable Value benefits from the use of future-visioning scenarios. The purpose of such scenarios is not to predict the future but to get ready for change. Visualizing possible futures helps broaden perspectives and manage uncertainties. Shell Oil in 1967 began a scenario-planning exercise under Pierre Wack before the oil crisis of 1973-74. Scenarios prepared in 1971 and 1972 outlined a possible future in which the power in oil markets would shift from consumers to producers (the OPEC nations). Shell was better prepared than the other oil majors and went from 7th to 2nd largest and most profitable of the so-called Seven Sister oil companies. In that era, corporations engaged in scenario planning but today's increased uncertainty and shorter time horizons lead us to prefer the concept of scenario design using abductive thinking based on incomplete information.

Today there is significant value in contemplating future uncertainties that question our habitual beliefs in economic growth, material consumerism, and globalization. How will businesses fare in a world in which economic growth trends to zero or negative? Consumers may increasingly seek nonmaterial products and services. Nationalism and regional forces combined with local governments may become the primary force behind economics and politics. Other uncertainties to explore are government regulation (high versus low), the shifting balance between individual rights and community responsibility, and nature degradation versus regeneration.

"Scenarios can help business leaders make more informed strategic decisions to cope with an uncertain world. " Jim Moffatt, Deloitte/World Economic Forum report [56].

In addition to scenario design, a dynamic approach to creating Sustainable Value requires the use of relatively new emerging frameworks and tools such as materiality, circularity, and regenerativity [57]. The use of such frameworks and tools becomes a practical necessity 
in a business environment characterized by declining natural resources, radical transparency, and rising societal expectations.

\section{Steps That Leaders and Organizations Can Take}

In the words of Peter Drucker, the Seven New Assumptions about the business environment re-define what an organization is paid for. They point to a new vision of how business can make a positive difference in the economy and society at large.

The following steps can help leaders and organizations begin the journey toward a better dynamic fit between the business environment and the company's purpose, leadership, and culture.

- Define what you're passionate about. Find or re-set your personal and organizational purpose. See yourself as a positive change agent for world benefit.

- Take an "outside-in" perspective that starts with the external environment and its key stakeholders. Focus outwards, not inwards, to make business strategy and operating decisions.

- Identify opportunities to fill gaps that serve markets and unmet social needs.

- Build on your unique strengths (resources, market access, skills, and experience.)

- Partner with economic and societal stakeholders inside and outside the organization. Connect their strengths to your strengths.

- Use design thinking and scenario building not as a way to predict the future but as a way to strength your adaptability and resilience in the face of unpredictability.

- Assemble as many key stakeholders as possible to discover shared strengths and to think beyond the possible as a way to deal with radical disruptions.

- Design your business model to create sustainable value with no trade-off between organizational and societal benefits.

- Periodically revisit your organizational purpose. Offer consistent guidance to your team no matter how tough the decisions are that have to be made.

- Take care of your inner self. Adopt practices that cultivate your whole person and increase your sense of connection to your life's purpose, others, nature, and the transcendent.

\section{Conclusions, Limitations, and Future Directions of Research}

This paper calls into question many deeply held beliefs that shape an organization's capacity to function and manage change in the face of disruptive global challenges. It draws on insights from Drucker and Burke-Litwin, among other sources on leadership and change management, to ask critical questions about how such beliefs or assumptions affect the relationship between an organization and its external environment. It builds on the work of Drucker [6] and more recently Donaldson and Walsh [38] to advance elements of a New Theory of Business needed to navigate effectively in complex, interconnected, and perpetually turbulent environments.

Our focus has been on organizational instances of "Doing Well by Doing Good". The concept of Positive Institutions moves the effectiveness discourse from a narrow definition of economic performance toward the greater purpose of flourishing for business and society. The Appreciative Inquiry Summit method combined with the framing of Sustainable Value offers a powerful approach to change management methods and tools to enable Positive Institutions. The paper suggests specific steps that leaders and organizations can take on their path to making a more positive difference in the economy and in the society at large.

Our contribution here is intended primarily as an early investigation into the emergence of Positive Institutions. The practical aspects of promulgating the Seven New Assumptions deserve further consideration. The goal is to invite research into the dynamic relationship between a firm and its complex and emergent external environment. Such research might explore how a stronger alignment or "fit" between them can improve organizational functioning and change management in ways that positively redefine the role of business in society. 
No attempt was made to study instances of businesses that do well for shareholders by doing harm to stakeholders. Such is the case for some (but not all) tobacco, pharmaceutical, and fossil fuel energy companies. Nor did we review instances of businesses that destroy value for their shareholders in spite of creating value for their stakeholders. The methodological and epistemological defense for such a selective research approach derives in part from findings in the aforementioned field of positive organizational scholarship (POS). Such findings propose that studying instances of positive-deviance provide both greater insight into what happens when "things go right" and greater influence in shaping desired institutional outcomes [58]. In other words, we advocate for the power and fatefulness of the questions we ask. Our questions are not neutral. If one seeks excellence in order to achieve world-class standards, then one needs to study moments of excellence.

Underlying our advocacy for Positive Institutions is evidence that doing good for society at the level of the whole enables businesses to do even better than they otherwise would at the individual organization level. A limitation of our paper is that it does not provide definitive evidence for such a positive relationship based on large data sets. However, it is important to note that the literature on corporate social responsibility (CSR) has by now dispelled the long-standing myth that CSR performance, which habitually has a mix of "doing less harm" and "making positive impact", must necessarily come at a cost to corporate financial performance [59]. While we are not aware of comprehensive empirical studies specifically on the performance correlates of Positive Institutions, the evidence for "doing well by doing good" is strong and growing. Money manager Joseph Bragdon documents case studies of such "living" businesses that outperform their peers [60]. His GLOBAL LAMP Index(C) contains 60 companies that together have outperformed comparable indices such as the Morgan Stanley Corporate International (MSCI) World Index and the Financial Times (FTSE) Global Index. The 22 public firms, 29 private firms, and 15 non-U.S. firms in another study, each purpose-driven to make a positive impact on society, outperformed the S\&P 500 by 14 times over a period of 15 years [61]. Our own research into Positive Institutions confirms these findings.

With these limitations in mind, we propose the following future directions for management research and practice. Practitioner-scholars may wish to develop the notion of dynamic fit between a firm and its external environment, drawing on systems thinking and complexity, to provide greater guidance on how to transform deeply held legacy beliefs or assumptions that many leaders hold. Such future research would build on the rich literature on sustainability mindset and leadership transformation. Scholars interested in theorizing may wish to foreground assumptions in the relevant literature on sustainability to uncover the ontology, epistemology, and even metaphysics of the methods and frameworks presented here. Doing so will create a stronger philosophical foundation for future research into Positive Institutions. Another rich avenue for study is the nature of the relationship between Positive Institutions and Corporate Financial Performance, by distinguishing instances of doing less harm from those aimed at making a positive impact, to conduct further empirical studies of the relationship between doing good and doing well.

Practitioners have the opportunity to build on the incipient work of this paper for leadership development, especially with the regard to the role of transforming leadership mindset. Additional areas that can benefit from applications of the theory and practices herein include social entrepreneurship, coaching, community partnerships, and employee wellbeing.

Author Contributions: This article is the result of a collaborative effort between C.L., D.C. and R.F. in areas of idea development, writing, and editing. C.L. led the effort and the authors discussed the contents of the article and the presentation of ideas throughout the writing period. All authors have read and agreed to the published version of the manuscript.

Funding: No funding was provided for this work other than that to cover staff and travel time and costs from each author's respective employers.

Conflicts of Interest: The authors declare that they have no conflict of interest. 


\section{References}

1. Why the Coronavirus Puts a New Lens on ESG Investing. Morgan Stanley. 6 April 2020. Available online: https: //www.morganstanley.com/ideas/coronavirus-corporates-esg-investing (accessed on 20 September 2020).

2. Big Business Pledged Gentler Capitalism. It's Not Happening in a Pandemic. New York Times. 23 April 2020. Available online: https://www.nytimes.com/2020/04/13/business/business-roundtable-coronavirus.html (accessed on 20 September 2020).

3. 50 Ways Companies Are Giving Back during the Corona Virus Pandemic. Available online: https://www.forbes.com/sites/blakemorgan/2020/03/17/50-ways-companies-are-giving-back-duringthe-corona-pandemic/\#1cd99a994723 (accessed on 20 September 2020).

4. AIM2Flourish Is a Platform Hosted by the Fowler Center for Business as an Agent of World Benefit at Case Western Reserve University. Available online: www.AIM2Flourish.com (accessed on 20 September 2020).

5. Understand the Five Most Important Questions to Ask about Your Business. Drucker School Business Performance Basics. Personal communication from Vijay Sathe, a Colleague of Peter Drucker and Chaired Professor at the Drucker School of Management, Claremont Graduate University. Available online: https:/trailhead.salesforce.com/en/content/learn/modules/drucker_five_most_import_questions/ drucker_five_five_most_import (accessed on 20 September 2020).

6. Drucker, P. The Theory of the Business Harvard Business Review; Harvard Business Review: Boston, MA, USA, 1994; pp. 95-104.

7. Shrivastava, P.; Zsolnai, L. Business and Society in the Anthropocene. In Sustainability (Business and Society 360); Wasieleski, D.M., Weber, J., Eds.; Emerald Publishing Limited: Bingley, UK, 2020; Volume 4, pp. 3-15.

8. Burke, W.W.; Litwin, G.H. A Causal Model of Organizational Performance and Change. J. Manag. 1992, 18, 523-545. [CrossRef]

9. Dissipative Structures Are Physical or Chemical Systems in Far-from-Equilibrium Conditions That Appear to Develop "Order out of Chaos" and Look to Be "Self-Organizing". The Information Philosopher Profile of Ilia Prigogine. Available online: http://informationphilosopher.com/solutions/scientists/prigogine/ (accessed on 20 September 2020).

10. The Mont Pelerin Society (MPS) Continues to Function to This Day. Available online: https://www. montpelerin.org/ (accessed on 20 September 2020).

11. Laszlo, C. Sustainable Value: How the World's Leading Companies Are Doing Well by Doing Good; Stanford University Press: Stanford, CA, USA, 2008; Chapter 10.

12. Johnson, A.E. I'm a Black climate expert. Racism derails our efforts to save the planet. The Washington Post, 3 June 2020.

13. Meadows, D. Places to Intervene in a System (Whole Earth. Winter 1997). Available online: http: //www.wholeearth.com/issue/2091/article/27/places.to.intervene.in.a.system (accessed on 20 September 2020).

14. The Four Rules of Pandemic Economics. The Atlantic. 2 April 2020. Available online: https://www.theatlantic. com/ideas/archive/2020/04/new-laws-pandemic-economics/609265/ (accessed on 20 September 2020).

15. Seligman, M.E.P. Flourish: A Visionary New Understanding of Happiness and Well-Being; Free Press: New York, NY, USA, 2011.

16. Denton, E. A Study of Spirituality in the Workplace. Sloan Manag. Rev. 1999, 40, 83-91.

17. World Economic Forum. 24 April 2020. Available online: https://www.weforum.org/agenda/2020/04/covid19coronavirus-climate-jennifer-morgan-greenpeace/ (accessed on 20 September 2020).

18. Burnes, B.; Jackson, P. Success and Failure in Organizational Change: An Exploration of the Role of Values. J. Chang. Manag. 2011, 11, 134. [CrossRef]

19. Dave, D.M.; Friedson, A.I.; McNichols, D.; Sabia, J.J. The Contagion Externality of a Superspreading Event: The Sturgis Motorcycle Rally and COVID-19; IZA Institute of Labor Economics: Bonn, Germany, 2020.

20. Reagan, R. Inaugural Addresses of the Presidents of the United States: Ronald Reagan. Avalon Project—Documents in Law, History, and Diplomacy. Available online: https://avalon.law.yale.edu/subject_ menus/inaug.asp (accessed on 20 September 2020).

21. Henderson, R. Reimagining Capitalism in a World on Fire; Public Affairs/Hachette: New York, NY, USA, 2020; p. 205.

22. Regilme, S., Jr. The decline of American power and Donald Trump: Reflections on human rights, neoliberalism, and the world order. Geoforum 2019, 102, 157-166. [CrossRef] 
23. Ice Core Data between 2.7 Million Years Ago and 1958. Daily Observations from the Mauna Loa Observatory in Hawaii Since 1958. For the Scripps Keeling Curve. Available online: https://sioweb.ucsd.edu/programs/keelingcurve/wp-content/plugins/sio-bluemoon/graphs/mlo_ full_record.png (accessed on 20 September 2020).

24. Hoegh-Guldberg, O.; Jacob, D.; Bindi, M.; Brown, S.; Camilloni, I.; Diedhiou, A.; Djalante, R.; Ebi, K.; Engelbrecht, F.; Guiot, J.; et al. Impacts of $1.5^{\circ} \mathrm{C}$ Global Warming on Natural and Human Systems; IPCC Secretariat: Geneva, Switzerland, 2018; Chapter 3.

25. The Stockholm Resilience Center's Research on Planetary Boundaries. Available online: https://www. stockholmresilience.org/research/planetary-boundaries.html (accessed on 20 September 2020).

26. Bamber, J. Scientific Integrity, Personal Responsibility, Public Trust and the Role of Professional Societies. In EGU General Assembly Conference Abstracts, 22nd ed.; 4-8 May 2020; Available online: https://ui.adsabs. harvard.edu/abs/2020EGUGA.2222690B/abstract (accessed on 20 September 2020).

27. Grieten, S.; Lambrechts, F.; Bouwen, R.; Huybrechts, J.; Fry, R.; Cooperrider, D. Inquiring into Appreciative Inquiry: A Conversation with David Cooperrider and Ronald Fry. J. Manag. Inq. 2018, 27, 101-114. [CrossRef]

28. Business and Sustainable Development Commission. Better Business, Better World Report; WEF: Cologny, Switzerland, 2017; pp. 10-62.

29. Stories of Business Innovations for Global Good. Available online: https://aim2flourish.com (accessed on 20 September 2020).

30. Positive Organizational Scholarship; Cameron, K.; Dutton, J.; Quinn, R. (Eds.) Berrett-Koehler: Oakland, CA, USA, 2003; pp. 3-13.

31. Fowler Center for Business as an Agent of World Benefit, Weatherhead School of Management, Case Western Reserve University; 5th Global Forum Concept; 2020. Available online: https://weatherhead.case.edu/centers/fowler/ (accessed on 20 September 2020).

32. Frederickson, B.L.; Coffey, K.A.; Pek, J.; Cohn, M.A.; Finkel, S.M. Open Hearts Build Lives: Positive Emotions, Induced through Loving-Kindness Meditation, Build Consequential Personal Resources. J. Personal. Soc. Psychol. 2008, 95, 1045-1062. [CrossRef] [PubMed]

33. Annan, K. Address to World Economic Forum. 30 January 1998. Available online: https://www.un.org/press/ en/1998/19980130.SGSM6448.html (accessed on 20 September 2020).

34. Stacey, R. Complex Responsive Processes in Organizations; Routledge: Abingdon, UK, 2001.

35. Markos, S.; Sridevi, M.S. Employee Engagement: The key to improving performance. Int. J. Bus. Manag. 2010, 5, 89-96.

36. Albrecht, S.L. Work engagement and the positive power of meaningful work. In Advances in Positive Organizational Psychology; Bakker, A.B., Ed.; Emerald Group Publishing: Bingley, UK, 2013; pp. 237-260.

37. UNGC-Accenture Report; The UN Global Compact-Accenture CEO Study on Sustainability; 2013. Pre-Publication Draft Available as PDF. Available online: http://www.ecdc.net.cn/2013gssd-unep/the\% 20un\%20global\%20compact-accenture\%20ceo\%20study.pdf (accessed on 20 September 2020).

38. Donaldson, T.; Walsh, J.P. Toward a theory of business. Res. Organ. Behav. 2015, 35, $181-207$. Available online: http://www.jamespwalsh.com/Resources/Donaldson\%20and\%20Walsh\%20-\%202015\%20\%20Toward\%20a\%20Theory\%20of\%20Business-1.pdf.183 (accessed on 20 September 2020).

39. Chen, X.; Thomas, F. Kelly. B-Corps-A Growing Form of Social Enterprise: Tracing Their Progress and Assessing Their Performance. J. Leadersh. Organ. Stud. 2014, 22, 102-114. [CrossRef]

40. Sumpter, D. My Interview with Aleksandr Kogan: What Cambridge Analytica Were Trying to Do and Why Their Algorithm Doesn't Work. Medium Blog. 22 April 2018. Available online: https://medium.com/@Soccermatics/my-interview-with-aleksander-kogan-what-cambridge-analyticawere-trying-to-do-and-why-their-f869ef65d945 (accessed on 20 September 2020).

41. Kell, G. Covid-19 Is Accelerating ESG Investing and Corporate Sustainability Practices. Forbes Online. 19 May 2020. Available online: https://www.forbes.com/sites/georgkell/2020/05/19/covid-19-is-acceleratingesg-investing-and-corporate-sustainability-practices/\#7e0036dd26bb (accessed on 20 September 2020).

42. Gow, G. Environmental Sustainability and AI. Forbes Online. 21 August 2020. Available online: https://www.forbes.com/sites/glenngow/2020/08/21/environmental-sustainability-and-ai/\#457c3e937db3 (accessed on 20 September 2020).

43. Richard, M.; Lutz, A.; Davidson, R. The Mind of the Meditator. Three forms of meditation (focused attention, open-monitoring, and loving-kindness) are shown to rewire brain circuits. Sci. Am. 2014, 311, 38-45. 
44. Laszlo, C. Quantum Management: The Science and Practices of Flourishing Enterprise. J. Manag. Spiritual. Relig. 2020, 17, 301-315. [CrossRef]

45. Tsao, F.; Laszlo, C. Quantum Leadership: New Consciousness in Business; Stanford University Press: Redland, CA, USA, 2019.

46. Glavas, A.; Kelley, K. The effects of perceived corporate social responsibility on employees. Bus. Ethics Q. 2014, 24, 165-202. [CrossRef]

47. Pirson, M. Humanistic Management: Protecting Dignity and Promoting Well Being; Cambridge University Press: Cambridge, UK, 2017.

48. Cooperrider, D.; Fry, R. Mirror Flourishing and the Positive Psychology of Sustainability. J. Corp. Citizsh. 2012, 46, 3-12. [CrossRef]

49. Yaden, D.B.; Iwry, J.; Slack, K.J.; Eichstaedt, J.C.; Zhao, Y.; Vaillant, G.E.; Newberg, A.B. The overview effect: Awe and self-transcendent experience in space flight. Psychol. Conscious. Theory Res. Pract. 2016, 3, 1-11. [CrossRef]

50. Cooperrider, D. The Concentration Effect of Strengths: How the whole system Appreciative Inquiry Summit brings out the best in human enterprise. Organ. Dyn. 2012, 41, 106-117. [CrossRef]

51. Cooperrider, D.; Sherman, D.; Woychik, E. Strategic Convening for Generative Impact: Enabling Systemic Change in Complex Environments. In Organizational Generativity: The Appreciative Inquiry Summit and a Scholarship of Transformation; (Advances in Appreciative Inquiry); Emerald Group Publishing Limited: Bingley, UK, 2013; Volume 4.

52. Quinn, R.E. Change the World: How Ordinary People Can Achieve Extraordinary Results, 1st ed.; Jossey-Bass: San Francisco, CA, USA, 2000.

53. Cooperrider, D.; Laszlo, C. The Sustainable Design Factory. Appreciative Inq. Pract. 2012, 14, $29-34$.

54. McQuaid, M.; Cooperrider, D. Your Change Blueprint: How to Design an Appreciative Inquiry Summit; McQuaid Pty Ltd.: Melbourne, Australia, 2018.

55. Laszlo, C. The Sustainable Company: How to Create Lasting Value through Social and Environmental Performance; Island Press: Washington, DC, USA, 2003; p. 126.

56. Schwab, K. Shaping the Future of Global Food Systems: A Scenarios Analysis. In World Economic Forum Report; 2017; p. 2. Available online: https://www.weforum.org/whitepapers/shaping-the-future-of-globalfood-systems-a-scenarios-analysis (accessed on 20 September 2020).

57. Hutchins, G.; Storm, L. Regenerative Leadership: The DNA of Life-Affirming 21st Century Organizations; Wordzworth Publishing: Royal Tunbridge Wells, UK, 2019.

58. Cameron, K.S.; Dutton, J.E.; Quinn, R.E. An introduction to Positive Organizational Scholarship. In Positive Organizational Scholarship; Berrett-Koehler: Oakland, CA, USA, 2003; pp. 3-13.

59. Friede, G.; Busch, T.; Bassen, A. ESG and Financial Performance: Aggregated Evidence from More than 2000 Empirical Studies. J. Sustain. Financ. Invest. 2015, 5, 210-233. [CrossRef]

60. Bragdon, J. Companies That Mimic Life: Leaders of the Emerging Corporate Renaissance; Routledge: Abingdon, UK, 2016.

61. Sisodia, R.; Sheth, J.; Wolfe, D. Firms of Endearment: How World Class Companies Profit from Passion and Purpose, 2nd ed.; FT Press: New York, NY, USA, 2014.

(C) 2020 by the authors. Licensee MDPI, Basel, Switzerland. This article is an open access article distributed under the terms and conditions of the Creative Commons Attribution (CC BY) license (http://creativecommons.org/licenses/by/4.0/). 